\title{
The Conflict Between African Cultural Practices and Western Occupational/Organizational Needs
}

\author{
Mapula Mojapelo-Batka \\ University of South Africa, South Africa
}

\begin{abstract}
Ritual has a symbolic meaning and therapeutic effect within the African culture. However, the opportunity to respectfully go through the prescribed rituals (specifically bereavement rituals) often interferers with the needs and belief system of the corporate western world. This poses a challenge for the bereaved person, the employer, and the therapist. In most instances, the resolution to this challenge takes a form of adjusting the ritual or cultural practice in order to accommodate the occupational needs. More and more African (especially in the urban context) do not go through the bereavement rituals due to occupational pressure and this may lead to the extinction of these significant cultural practices. Case studies were used to investigating the causes and impact of the change in the traditional African bereavement rituals. Thematic analysis of the cases and the results confirmed the need to develop ways of integrating the traditional African and western value systems. The implication of the identified conflict on the organization, with reference to absenteeism, low productivity, and reduced job satisfaction, needs to be investigated.
\end{abstract}

Keywords: cultural conflict, cultural practices, African culture, traditional culture, western culture, bereavement rituals, occupational/organizational needs

\section{Introduction}

This article focuses on the conflict between African cultural practice and western occupational/organizational needs. It highlights the dilemma faced by many Black South African workers who are constantly experiencing a mismatch between their culture practices and the culture of the South African organizations which is western in nature (Mjoli, 1987). Three broad categories of African cultures and persons were identified, those whose believes and practices are entrenched in the traditional African culture, those who practice a mixture of western culture and traditional African culture, and those who exclusively practice western culture (Prozesky, 2002; Peltzer, 1999). The focus of this article will be on the traditional African culture and persons.

Within the African culture, different phases of life are characterized by a set of culturally prescribed rituals. Rituals have a symbolic meaning and therapeutic effect within the African culture. However, the opportunity to go through the prescribed rituals (specifically bereavement rituals) respectfully often interferes with the needs and belief system of the corporate western world. This poses a challenge for the bereaved person, the employer, and the therapist. In most instances, the resolution to this challenge takes a form of adjusting the ritual or

Mapula Mojapelo-Batka, Ph.D., senior lecturer, Department of Psychology, University of South Africa. 
cultural practice in order to accommodate the occupational needs. More and more African (especially in the urban context) do not go through the bereavement rituals due to occupational pressure and this may lead to the extinction of these significant cultural practices.

African bereavement rituals will be utilized in this article to illustrate the conflict between culturally prescribed rituals and the needs of the western organizations. This does not imply that there are universally African culture and bereavement rituals. There are differences in the different African ethnic groups and any attempt to isolate or discuss the African culture or value system will fail to justify the complexity of the situation. It, however, appears that a number of cultural rituals and values do occur frequently enough in Africa to be regarded as typical or traditional.

Clinical case studies illustrating the negative emotional impact (such as guilt and depression) of these changes on the African worker will be presented and suggestions on possible ways to accommodate both the needs of the workers and the organization will be reviewed. Mjoli (1987) suggested the possibility and implication of "westernizing the Africa worker" or "Africanizing the organizations". Prozesky (2002) suggested that in not understanding the dynamics of the interface between these two value systems, most of the problems appear to arise in the business environment.

\section{Background Literature}

\section{Bereavement Rituals}

Cultural practices seem to acknowledge the wisdom of expressing grief. Not all cultures, however, handle this expression in the same way (Lalande \& Bonanno, 2006). Many cultures surround the death of one of its members with elaborate ceremony while others acknowledge the loss more privately. The cultural rituals for dealing with death, such as wakes and funerals, are designed to offer us an opportunity to express our sadness in the socially and culturally accepted manner. Participating in the ceremony and ritual of bereavement also seems to aid family and friends in the adjustment to losing the loved ones. Nwoye (2005) emphasized the important contribution of the African community and rituals in facilitating healing in the bereaved. He argued that western researchers and writers have largely been concerned with the individual's reaction to loss, the African perspective focus on the spiritual/systemic/interactional nature of healing in grieving and the resources that the community makes available to bereaved persons (Nwoye, 2005).

\section{Religion and Cultural Practices}

Shorter (1978) argued that religion and traditional African culture are inextricably intertwined. Most of the religious rituals are appropriated into the cultural scheme of things and the cultural domain shapes and influences the religious philosophy and practices. Shorter (1978) further argued that any attempt to dichotomize African spirituality into the sacred and the secular, the physical and the spiritual, the individual and the corporate, results in gross distortion and misconstrue of its theology and its praxis.

\section{The Conceptualization of Death Within the African Context}

According to Seleti and Ngubani (2005), the African conceptualization of death is based on the belief that there is a reciprocal relationship between the ancestral spirits and their descendants. The descendants have a duty to perform ritual acts which promote the acquisition of ancestral status of the spirit of the newly departed, which on attaining the right position in the ancestral realm is able, in conjunction with the rest of the ancestral spirits, to protect and bless the descendants. Similar conceptualization of death and African worldview of the 
interconnectedness of the activities of the living and the deceased family members were identified within the sub-Saharan African culture (Sow, 1980) and the Nigerian culture (Nwoye, 2011).

Death, like many rites of passage within the traditional African culture, has certain culturally prescribed rituals, such as slaughtering a beast female chief mourner sitting on the mattress for the whole period before the burial and wearing black clothes. The rituals prescribed for man are usually prescribed for the whole family (Radzilani, 2010).

Seleti and Ngubani (2005) indicated that while traveling along this purification journey, the spirit of the deceased is alone in the dark and in the wilderness. It is assisted by the support of the living kin who through their mourning observances share the sense of loneliness and withdrawal from the normal pleasantries of life. The companionship is expressed especially through the chief mourner whose behavior patterns focus her/his mind and body on enabling the departed spirit to reach the destination.

Both the departed spirit and the kinship group would have gone through two traumatic experiences with the occasion of death. For the departed spirit, the trauma is not only the wrenching of the spirit from the human body, but also its separation from visible society. Equally for the close kin, death means they have lost one of their important members, they must learn to accept and adjust to that loss. For both the living and the spirit of the recently deceased, life after death and bereavement, means a period of uncertainty, adjustment, and contemplation.

It is also a dangerous period in that if the living kin abandon the spirit on its purification journey, it might never reach the desired ancestral realm. De Villiers (1985) indicated that this belief system is used as the justification for illness and misfortune for the descendants of the Xhosa-speaking culture. It would continue wondering in the valley of spiritual wilderness without end. Thus, there are sets of rituals that are performed by the living in order to help the spirit of the deceased to reach a full cycle of the spiritual life (Seleti \& Ngubani, 2005).

\section{The Symbolic Meaning of Bereavement Rituals Within the Traditional African Context}

A clear visible connection between the body of the ancestral spirit or newly-departed spirit is usually symbolized by:

(1) Wearing specific identifiable clothes, usually black clothes, by the chief mourner for a period of one year, if the deceased was in late adulthood, six months for an adult or a period of three months for a young person. The duration of the phase of mourning is determined by the responsibilities of the deceased as presented above (Rowland, 2002; Sossou, 2002);

(2) Slaughtering an animal and the night vigil. In the event of the death of the male head of the family, a male beast would be slaughtered, this usually symbolizes the death of the head of the family (Bodibe, 1993);

(3) Sitting on the bare mattress by women mourners for the whole period prior to the funeral service. This could be based on the belief that women are more emotionally traumatized by the death of a loved one than males (Sossou, 2002). When community members bring condolences, they are usually directed to the bereaved woman sitting on the mattress (Rowland, 2002; Rosenblatt \& Nkosi, 2007);

(4) Avoiding certain places, for example, grave yards and being away from home at night. This is possibly based on the belief that the bereaved is going through a phase of darkness (what is referred to as sififi) and being in places like that could lead to more pain, sadness, and trauma (Manganyi, 1987). 
Sossou (2002) indicated that failure to fulfill any of the above culturally prescribed seclusion rituals may result in being blamed by the family and/or community members for killing the deceased family member, a sign of disrespect for the deceased and/or lack of public display of the expected sadness after the loss of a loved one.

After an appropriate duration of time after death, there are rituals that are performed to separate the chief mourner from the close connection with the spirit of the deceased, thereby integrating her back into society, taking off the prescribed cloths, shaving your hair (all the hair) by the rest of the family members, and cleansing and burning the clothes and hair as a symbol of breaking from the past. This is usually done at the stage when the purification phase is completed and is regarded as a symbolic meaning of a new beginning of re-adjustment to life without the deceased (Seleti \& Ngubani, 2005; Rosenblatt \& Nkosi, 2007; Sossou, 2002; Ambasa-Shisanya, 2007; Selepe \& Edwards, 2008).

Meanwhile, the same rituals complete the purification of the spirit of the deceased enabling it to be integrated with the body of ancestors. The duration of time is measured in accordance with the responsibilities that the deceased undertook while alive. As a married person, for instance, he/she would have had a heavier load of social and religious responsibilities compared to that of a child or an infant. This high level of responsibility leaves much chance of making many mistakes. As a result, those who had reached adulthood with its many duties are more likely to be more tarnished than the young. Therefore, the spirits of the deceased adults spend a longer time before integration with the body of ancestral spirits than the spirits of the junior members of society.

The above symptoms and duration of the bereavement phase described from an African perspective seem to be universally experienced and acceptable and are recognized by the DSM (diagnostic statistical manual)-1V-TR (APA (American Psychiatric Association), 2000). The manual is a universal tool for the classification of mental illness and symptoms. What is unique to the traditional African culture is the meanings attached to the processes before and after the loved one pass away. While western research and writings on bereavement have given enormous emphasis to the influence of intrapsychic factors over the process and experiences around grieving and mourning, there are arguments suggesting a move towards the creation of psychology and services that are culturally appropriate (Cooper, 2007; Painter \& Terre Blanche, 2004; Holdstock, 2000; Nwoye, 2005).

\section{The Therapeutic Value}

On the spiritual level, a well completed bereavement ritual might lead to a sense of accomplishment, peace, health, and well-being. Boyden (1997), Hammond-Took (1986), Honwana (1999), De Villiers (1985), and Radzilani (2010) have shown that an uncompleted or interrupted bereavement ritual might lead to guilt and fear which might result in symptoms of depression. This complication might be followed by the need to appease the ancestor through "Go Phasa Badimo". This is the traditional therapeutic treatment or practice to correct what is believed to be wrong (Bodibe, 1990, 1992; Thabede, 1991).

On the community level, people are more empathic and supportive to a grieving person. This might be out of sympathy, or due to the fear that the phase that the bereaved is going through might be infectious and bring misfortunes (sefifi). The support and the sympathy that the bereaved receive might lead to a reduction of the feelings of depression. In this way, bereavement becomes a community process rather that an individual process (Mbiti, 1969; Mabotoa, 1994; Oosthuizen, 1991; Setiloane, 1979; Nwoye, 2005). 
As indicated in the discussion above, all these rituals are necessary steps to recover from the loss and to facilitate the integration of the departed spirit to rest in peace. This belief system and practices also help in developing an understand to some of the national processes, such as the South African truth and reconciliation commission and the place of Freedom Park in the management of the spirit of those who fell during the armed struggle.

This processes had a dual purpose, which was not just reconciling with those that have inflicted pain, but also to allow the families of those who have lost their loved ones to mourn appropriately and release the spirit of the deceased to integrate with the ancestral world and to reach a full cycle of the spiritual life. This reflects a common African expression "Badomo ba go robaletse", a comment usually accompanied by a feeling of success, fortune, and well-being (De Villiers, 1985; Nyamiti, 1990).

\section{Differences Between Traditional African Values and Western Occupational Values}

Bodibe (1993) reported that after the abolishment of the group areas acted in South Africa, a number of Black South Africans moved to areas that were predominantly white. These Blacks were soon to discover that the slaughtering of beasts during funerals and the holding of night vigils contravened the laws of local authorities in these areas. Slaughtering any animal can only take place at the abattoirs and singing and preaching in the night vigils are regarded as disturbance of public peace. This ritual forms the very essence of handling grief and bereavement in African societies. Bodibe (1993) indicated that the curative and cathartic effect of the rituals lowered significantly among Black African people.

Prozesky (2002) identified and described seven differences between traditional African values and global western business values. These differences include:

Firstly, community above individualism - It was said by traditional Africans that there was insufficient sense of community in people with western traditions, to whom it was the individual that counted. To the traditional African, the community came first.

Secondly, external not internal control - to "the westerner" - the key control is within the individual who must take the right strategic decisions - the entrepreneurial sense makes success. Traditionalist Africans have strong external controls - in some sense, they may feel powerless in the face of their ancestors.

Thirdly, supportiveness above competition-It is seen by traditionalist Africans as dehumanising to just compete - the individual is not "number one".

Fourthly, people, not workers/staff-People should be treated as people, not workers and staff.

Fifthly, qualitative time-Time should not be determined entirely quantitatively in terms of clocks etc., but qualitatively. How this is managed in a global business perspective is a difficult question but this has to be accommodated.

Sixthly, leadership through care and integrity, not power and status-For traditional Africans status will produce fear and some results but not co-operation.

Seventhly, holistic wealth—For traditional Africans what is the point of success in business, if it does not lead to cordial relationships, if wealth is not available and beneficial to all.

The comparison made above between African and global business values is effectively, therefore, a comparison of western secular values and traditional African values. Prozesky (2002), Godsell (1983), Hofstede (1980), Nurnberger (1994), and Tabane (1981) suggested that in not understanding the dynamics of the interface between these two value systems, problems and misunderstanding appear to arise in the business environment.

Mjoli (1987) described the above conflict as the person-environment mismatch that is characteristic of many organizations in South Africa. Mjoli (1987) defined the person-environment mismatch as a situation 
where organizations and their practices in South Africa are western in cultural orientation, while the Black workers are African in cultural orientation. Mjoli (1987) suggested that the person-environment mismatch might be managed in two ways: westernizing the African (that is changing the cultural and value systems of the African), or Africanizing the organization (changing the organization to a point where the values and culture of the African workers are taken into account).

Westernizing the African seems to create emotional conflict and removes Africans from their all important cultural roots for the benefit of the western enterprise. Africanizing the organization which Moerdyk and Coldwell $(1981 ; 1982)$ referred to as "cultural synergy" and Muzorewa (1985) and Pobee (1979) referred to as syncretism, seems to be more effective. It takes into account the needs of the African worker, as well as the needs of the organization without valuing the one more than the other. These approaches seemed to be less exploitative.

Thorsrud (1981) suggested that the authorities of the organizations can put a stamp of approval and accept that absenteeism is unavoidable, training other employees to take over when others are absent, introducing a system of paying for actual work done rather than time spent at work, and giving productivity bonuses to high-producing employees, as another way of Africanizing the organization in relation to the issue of time needed to go through bereavement ritual and addressing the effect absenteeism might have on productivity at work.

The review of the literature above indicated the complexity of the conflict between the western and traditional values systems. What follows now is the method that has been used to understand these conflicts.

\section{Methodology}

The study adopted a case study methodology. Four cases will be used in this article. The author was engaged with two clients that presented in psychotherapy with difficulties in going through the culturally prescribed bereavement ritual due to occupational needs and demands. All these cases were presented within a period of two months during 2010. The common themes that were identified in the presented cases inspired the author to investigate the subject even further. A client-centered method of therapy was conducted with the two presented problems. Client-centered therapy is non-directive and non-judgemental processes of facilitating the expressions of feelings and experiences.

Clinical files were used to collect the data regarding the experiences of the client. Two therapists (who were trained and used client-centered therapy) who had previously dealt with similar cases were interviewed. Notes were made from the report that was given by the therapist. Their reports are included as scenarios with the aim of including as many experiences as possible.

The age, gender, socio-economic, and occupational context of the clients varied were considered. The effect of these factors seems insignificant to the presented problem.

The materials used in this article were from the process notes that were used in the sessions. The sessions were ranged in 3-5 sessions, with 60 minutes each, with a frequency of one session per week. The sessions were analysed using thematic content analysis and were used in comparison with literature around the topic of bereavement rituals within the African context and the western needs.

Permission to use the case material was abstained from the clients that the author consulted. The clients were assured of confidentiality as any identifying information from the client's file was excluded from this article. 


\section{Presentation of Clinical Cases to Illustrate the Challenges Facing Meeting the Needs of the Bereaved vs. the Needs of the Organization}

\section{Case 1}

A man lost his wife. It was culturally prescribed that, as part of the ritual he has to be home every day before sunset for a period of six months. He wanted to go through all the prescribed rituals but he was expected to work night shifts. He arranged with one of his colleagues to assist him by doing the night shifts for him. The employer complained that he was the most effective employee to facilitate good production with that night shift group and that he needed to be in the rotating team. The employer did not recognize this cultural practice and no efforts were made to assist in allowing the employee to respectfully go through the prescribed ritual. He was told that if he did not want to work night shift, they would replace him with someone who was more serious about his work.

The man negotiated with his colleague to take night shift for the prescribed period of the cultural ritual. The colleague agreed but after the second months, it was impossible to continue with the arrangement and there was no substitute available.

The man felt fearful for being unable to complete the ritual and feared that the spirit of his wife might not rest in peace. He was constantly concerned about the implications or misfortunes that he might experience because of this interruption in the process of the prescribed ritual. He was also concerned about losing his job, since he had already lost so much. His family advised him to save his job.

The elders were invited to negotiate with the ancestors to adjust the prescribed ritual in order to accommodate his occupational needs and demand. He continued feeling angry and frustrated. He felt a sense of having failed his wife, his family, and community. He felt he had to explain himself and his situation when he met people from his community after the might shift. He complained about sleeplessness, irritability, and lack of concentration at work especially during night shifts.

\section{Case 2}

A client consulted a clinical psychologist for counseling after she requested leave from work (three days before the funeral) to be able to prepare for her parents' funeral and needed money in advance to be able to buy a cow for the funeral process/ritual. The employer responded by blaming her taking too many leave days for funerals and for wasting money on people that had nothing to do with the deceased and the family (the community at large). The manager further said "I think you people must change your culture, it is backward, and it is not cost effective". All these statements were said in a way that ridiculed the cultural practices.

The woman felt traumatized, rejected, blamed, and a sense of conflict. The comments of the employer induced embarrassment and guilt in this woman, to a point where, she questioned her own cultural belief system.

The two last cases involve women who had lost their husbands and were culturally expected to wear black cloth for an uninterrupted period of about one year.

\section{Case 3}

One of the women was removed from the front desk as a public admin officer. Her employer complained that her black cloths interfered with the company image. She indicated that she understood the employer's concern as the company had a high profile, but at the same time, felt that the manager did not understand her 
culture. She also reported that if she was not working, it would be much easier for her to mourn her husband's death as the family prescribed. The idea of re-negotiating with her manager about the black cloths was not even considered, because the client did not feel it would be successful. She stated, "Within our company, image is very important". The client was grateful that she had a job and did not want to risk losing it, especially now that she was a breadwinner in her house. She indicated that she needed something to help her cope with her feeling of worthlessness and isolation that came with the new job placement. She also reported that she was coping with her loss well and only started experiencing problems, such as sleeplessness, loneliness, and worthless after the new job placement. She was feeling sad and regarded her placement at the back office as a demotion. This led to feeling of insignificance and feeling of being unfulfilled. She was also removed from the social contact and possible social support that she was receiving from some of the company clients.

\section{Case 4}

Women working in the hospital hotel/catering context are expected to wear the white uniform. Within this context, white symbolizes hygiene and cleanness. This occupational symbol is in direct conflict with the prescribed cultural ritual of wearing black to symbolize a phase of impurity or uncleanness. The client and her manager did not have any problem with the black cloths. The complaints came from patients (mainly African patients) who complained that they do not feel safe to be treated by the grieving woman in black cloths as this could bring misfortune. The woman adjusted to this situation by changing her cloths every day in the toilet before going in the hospital ward and after work before going home. She presented in therapy, because her family in law was complaining about the arrangement and blaming her for the unwillingness to mourn for their son.

\section{Discussion and Integration of Results}

It is clear from the above cases that the conflict between the prescribed cultural rituals gets adjusted in order to meet the western occupational/organizational needs.

In the first case, the man could not continue with the grieving process due to occupational needs. Rituals to re-negotiate with the ancestors were performed, but he was still concerned and fearful about the implication of the disrupted bereavement ritual process. These findings confirmed the literature that suggested that failure to go through the ritual uninterrupted might result ill health. The results also confirmed the difficulty involved in changing cultural belief and value systems. This also confirmed the suggestion that westernizing the African might be very difficult to achieve, as it involved the changes in cultural value system.

In the second case, the comment of the manager created feeling of confusion and pressure to change African cultural values. The manager's comment resulted in negative feeling of embarrassment as the culture was described as backwards and not cost effective. The manager's comments might be due to lack of sensitive and knowledge about cultural diverse practices. This might more a personal limitation rather than occupational pressure. The result of the manager's lack of cultural sensitivity had negative emotional impact on the client and her grieving process.

In the third case, the woman accepted the suggestion to be place at the back office in order to maintain the company image. She, however, felt misunderstood and deprived of the support that she was receiving from the company clients. The results indicated that removal of the woman from the front office where she was easily identified as a grieving person and supported, which had more impacts on her grieving process. This confirmed 
the suggestion that wearing black clothes assist the bereaved woman as they are easily identifying as grieving and in pain, and might be socially supported. The understanding of the symbolic meaning and therapeutic value of the ritual on the part of the organization might have made the client's situation better.

In the fourth case, the pressure to adjust the cultural ritual was not directly from the organization but rather from the family in law and the African community at the hospital due to their traditional belief system. In this situation, the expected cultural rituals between the African people do not fit in with the prescribed western practices or values. It would be easier for the bereaved person to comply with the prescribed ritual within the rural or more traditional context. Bodibe (1993) reported that most African people that moved to urbanized communities where cultural practices, such as slaughtering a beast, were in conflict with the rulers of that community ends up discontinuing with the cultural ritual. These findings indicate the effect of urbanization on African cultural practices. One can argue, however that most organizations are in urban areas. Due to the need for economic resources and work, the African workers have to move to urban areas and for issues of practicality stay there. The western value systems and culture do not accommodate most African cultural practices.

\section{Conclusion}

The client's experiences indicate the differences between western values and traditional African values as described by Prozesky (2002). It is also clear that due to financial pressures and fear of unemployment, more and more cultural rituals are abandoned. The results also indicated that not going through the bereavement ritual seems to have a negative emotional impact. Guilt or fear, experienced by the bereaved person or induced by the social context commonly occurred. A feeling of sadness, confusion, and being misunderstood by the employers was also reported by some of the clients. The reports also reflect what Mjoli (1987) referred to as the person-environment mismatch that is characteristic of many organizations in South Africa.

The conflict between the African cultural practices and the western occupational/organizational needs will remain a challenge for the employer, the organization, and the therapist, if the two conflicting value systems remain as opposing value systems. The results confirm the need for cultural integration of both the western and traditional value systems. Just as the process of the indigenization of the health system, educational system and the church have been encouraged in South Africa and policies on integrating western and traditional value systems within these contexts are underway so organizations should follow suit. The indigenization and integration of the South African organizations might result in the development of policies that promote and respect all South African citizens equally.

The findings of this article might encourage movement away from the approach and belief system that is based on either the African culture or the western culture, to an appreciation of the richness and uniqueness which each culture adds to the South African context.

Based on the findings of this article, it is recommended that organizational authorities and managers be trained to acquire skills in dealing with cultural diversity issues. Such training should be aimed at raising their awareness and sensitivity to cultural diverse issues. It is also recommended that studies investigating the impact of this conflict on the organization, with reference to absenteeism, low productivity, and reduced job satisfaction be conducted. 


\section{References}

Ambasa-Shisanya, C. R. (2007). Widowhood in the era of HIV/AIDS: A case study of Siaya District, Kenya. Journal of Social Aspects of HIV/AIDS, 4(2), 606-615.

APA (American Psychiatric Association). (2000). Diagnostic and statistical manual of mental disorders (4th ed., Text Revision). Washington, D. C.: Author.

Bodibe, R. C. (1990). Traditional healing and western therapeutic approach—Adversaries or reluctant neighbor? In J. M. Mason, J. Rubenstein, \& S. Shuda (Eds.), From diversity to healing. Proceedings of The 5th Biennial International Conference of the South African Institute of Marital and Family Therapy.

Bodibe, R. C. (1992). Traditional healing: An indigineoius approach to mental health problems. In J. Uys (Ed.), Psychological counceselling in the South African context. Cape Town: Maskew Miller Longman.

Bodibe, R. C. (1993). What is the truth? Being more than just a jesting palate in South African psychology. South African Journal of Psychology, 23, 53-58.

Boyden, G. (1997). Children and war: Understanding psychological distress in Cambodia. Geneva: UN.

Cooper, S. (2007). Psychotherapy in South Africa: The case of Mrs. A. Journal of Clinical Psychology: In Session, 63(8), 773-776.

De Villiers, S. (1985). Consideration of illness causation among some Xhosa-speaking people. South African Journal of Ethnology, 8, 48-52.

Godsell, G. (1983). Work value differences in South African organizations: A study and some conclusions. Johannesburg: National Institute for Personnel Research, Council for Science and Industrial Research.

Hammond-Took, D. (1986). The role of culture in maintaining mental health. Psychotherapeia, 45, 2-18.

Hofstede, G. (1980). Culture's consequences: International differences in work related values. Sage: Beverly Hills.

Holdstock, T. L. (2000). Re-examining psychology: Critical perspectives and African insights. London, UK: Routledge.

Honwana, A. (1999). Negotiating post-war identities: Child soldiers in Mozambique and Angola. In G. Bond, \& N. Gibson (Eds.), Contested terrains and constructed categories: Contemporary Africa in focus. New York: Westview Press.

Lalande, K. M., \& Bonanno, G. A. (2006). Culture and continuing bonds: A prospective comparison of bereavement in the United States and the People's Republic of China. Death Studies, 30, 303-324.

Mabotoa, P. (1994). I am because we are; Because we are I am: Afrocentric view of mental health. Proceedings of The African Now Conference of the African Regional Council of the World Federation for Mental Health, University of the North West, Mafikeng, South Africa.

Manganyi, N. C. (1987). Psychology and the politics of experience. Papers presented at The 5th National Psychology Conference, Cape Town, September, 1987.

Mbiti, J. S. (1969). African religions and philosophy. London \& Nairobi: Heinemann.

Mjoli, Q. T. (1987). The role of the psychologist in culturally diverse South Africa. Development Southern, 4(1), 7-19.

Moerdyk, A. P., \& Coldwell, D. A. L. (1981). Paradigms apart: "Black managers in a white man's world”. South African Journal of Business Management, 12, 3.

Moerdyk, A. P., \& Coldwell, D. A. L. (1982). On fitting paradigms to people. South African Journal of Business Management, 4 , 13.

Muzorewa, G. (1985). The origins and development of African theology. Maryknoll, New York: Orbis Books.

Mzinyathi, B. D. (1994). Workshop for traditional healers and health professionals (Unpublished report, Port Elizabeth, South Africa).

Nurnberger, K. (1994). An economic vision for South Africa in the post apartheid economy. Pietermaritzburg: Encounter Publications.

Nyamiti, C. (1990). The church as Christ's ancestral mediation. In J. N. K. Mugambi, \& L. Magesa (Eds.), The church in African Christianity - Innovative essays in ecclesiology. Nairobi: Initiatives Publishers.

Nwoye, A. (2005). Memory healing processes and community intervention in grief work in Africa. ANZJFT, 26(3), 147-154.

Nwoye, C. M. A. (2011). Igbo cultural and religious worldview: An insider's perspective. International Journal of Sociology and Anthropology, 3(8), 304-317.

Oosthuizen, C. (1991). The place of traditional religion in contemporary South Africa. In J. K. Olupona (Ed.), African traditional religions in contemporary society. New York: Paragon House Publishers. 
Painter, D., \& Terre Blanche, M. (2004). Critical in South Africa: Looking back and looking ahead. South African Journal of Psychology, 34(4), 520-543.

Peltzer, K. (1999). Faith healing for mental and social disorders in the Northern Province (South Africa). Journal of Religion in Africa, $X X I X(3), 387-402$.

Pobee, J. (1979). Toward an African theology. Nashville, Abingdon.

Prozesky, M. (2002). African business value-A global perspective. Paper presented at The British Camber Discussion Group, University of Natal, Pietermaritzburg.

Radzilani, M. S. (2010). A discourse analysis of bereavement rituals in a Tshivenda speaking community: African Christian and traditional African perspective (Unpublished doctoral dissertation, University of Pretoria, Pretoria, South Africa).

Rosenblatt, P. C., \& Nkosi, B. C. (2007). South African Zulu widows in a time of poverty and social change. Death Studies, 31(1), 67-85.

Selepe, M. C., \& Edwards, S. D. (2008). Grieve counseling in African indigenous churches: A case of the Zion Apostolic church in Venda. Indilinga-African Journal of Indigenous Knowledge Systems, 7(1), 1-6.

Seleti, Y. N. (2004). Africa since 1990 Ed. Johannesburg: New Africa Education.

Seleti, Y. N., \& Ngubani, H. (2005). An African perspective on the management of life and death and its implications for nation building and reconciliation in South Africa. Pretoria.

Setiloane, G. (1976). The image of god among the Sotho-Tswana. Rotterdam, A. A.: Balkema.

Shorter, A. (1978). Spiritual writing in contemporary Africa. In A. Shorter (Ed.), African Christian spirituality. London: Geoffrey Chapman.

Sossou, M. A. (2002). Widowhood practices in West Africa: The silent victims. International Journal of Social Welfare, 11(3), 201-209.

Sow, I. (1980). Anthropological structures of madness in Black Africa. New York, N. Y.: International University Press.

Tabane, A. (1981). The socio-cultural background of the Black South African and its impact of business development: A position paper. School of Business Leadership, UNISA, Pretoria.

Thabede, D. G. (1991). The relevance of traditional healers in the provision of mental health services. Social Work Journal, 2 , 11-14.

Thorsrud, E. (1981). Giving absenttesm a stamp of approval. International Management, 36(1). 